\title{
Magnetic resonance appearance of recurrent ophthalmoplegic migraine
}

Aspectos de ressonância magnética na enxaqueca oftalmoplégica recorrente Antônio José da Rochaํ, Paulo Breinis², Mario Luiz R Monteiro ${ }^{3}$
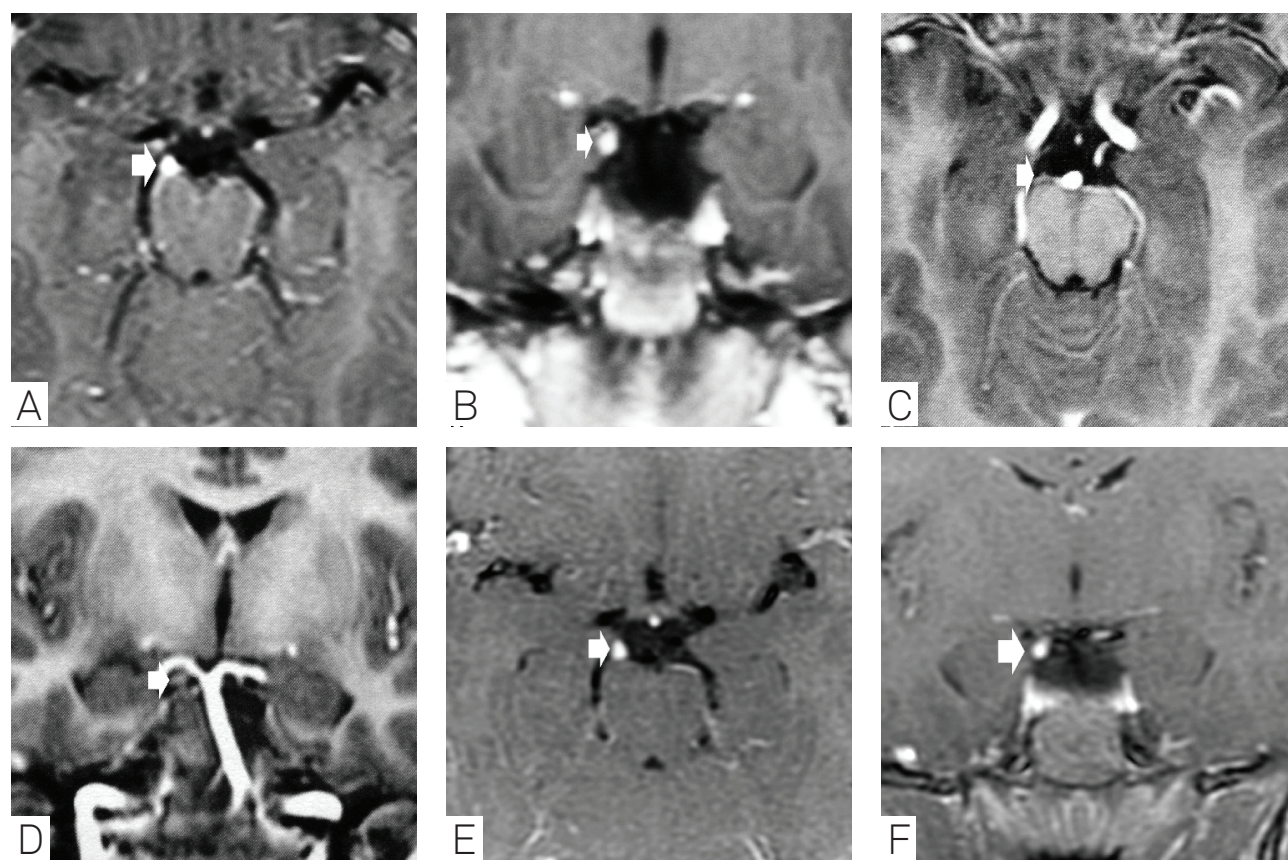

Figure. T1-weighted post-gadolinium axial and coronal images obtained during the initial episode (A-B) displayed typical focal thickening and enhancement of the proximal cisternal segment of the third right cranial nerve (arrows). (C-D) Comparative images taken 3 years later showed persistent focal thickening without evident enhancement (arrows). (E-F) Images obtained during the recurrence also showed thickening and enhancement (arrows).

A 5-year-old boy presented with severe frontal headache followed by right cranial nerve paresis. His previous medical history, blood tests and CSF analysis were unremarkable, and he made a full recovery after 4 weeks. Nevertheless, a similar episode occurred 5 years later. Magnetic resonance imaging follow-up supported diagnosis of recurrent ophthalmoplegic migraine (Figure).
This rare form of migraine, which mainly affects children ${ }^{1}$, may present as a triad of symptoms consisting of migraine ophthalmoplegia (nerve palsy) and focal enhancement of an enlarged third cranial nerve at the root exit zone. However, other diagnoses must be ruled out. The controversial pathogenesis of the condition may stem from the reversible breakdown of the blood-brain barrier due to vasospasm during the migraine attack or recurrent demyelinating neuropathy $y^{1,2}$.

\section{References}

1. Miglio L, Feraco P, Tani G, Ambrosetto P. Computed tomography and magnetic resonance imaging findings in ophthalmoplegic migraine. Pediatr Neurol 2010;42:434-436.
Bharucha DX, Campbell TB, Valencia I, Hardison HH, Kothare SV. MRI findings in pediatric ophthalmoplegic migraine: a case report and literature review. Pediatr Neurol 2007;37:59-63.

'Section of Neuroradiology, Fleury Medicina e Saúde, São Paulo SP, Brazil;

${ }^{2}$ Pediatric Neurologist, Faculdade de Medicina do ABC, Santo André SP, Brazil;

${ }^{3}$ Division of Ophtalmology and Laboratory of Ophtalmological Investigations (LIM-33), University of São Paulo Medical School, São Paulo SP, Brazil.

Correspondence: Antônio José da Rocha; Rua Cincinato Braga 232; 01333-910 São Paulo SP - Brasil; E-mail: antonio.rocha@fleury.com.br

Conflict of interest: There is no conflict to interest to declare.

Received 19 August 2011; Received in final form 15 September 2011; Accepted 22 September 2011 